\title{
ON THE ANATOMY
}

OF A

\section{CASE OF MOLLUSCUM FIBROSUM.}

\author{
BY \\ C. HILTON FAGGE, M.D., \\ ASSISTANT-PHYSICIAN TO, AND DFMONSTRATOR OF CUTANEOUS DISEASES AT, \\ GUY's HOSPITAL. \\ Received June 14th-Read June 28th, 1870.
}

Having recently had an opportunity of examining after death a case of Molluscum Fibrosum, I think it may be interesting to the members of this Society that I should bring the result of my investigation under their notice, more especially since the conclusions at which $I$ have arrived are not in accordance with the current doctrines on the subject.

Sarah E-, æt. 40, was admitted into Guy's Hospital, under the care of Dr. Braxton Hicks, suffering from abdominal disease, which was correctly diagnosed as of a malignant nature. A hard uneven mass could be felt through the abdominal walls, consisting of cancerous disease of the omentum.

Scattered over the trunk and limbs of the patient were 
innumerable tumours, occupying the skin and subcutaneous tissue. These were especially abundant on the trunk, but they also existed in considerable numbers on the limbs. They varied greatly in size; one of the largest, situated on the inner side of the right thigh, was as big as a walnut; most of them were much smaller. Some, especially on the back, were pedunculated, and were suspended from the surface of the skin; these were generally flaccid and flattened, evidently having been altered in shape by being pressed against the surface of the skin. Others lay beneath the cutis, each forming a flattened prominence, in which a lenticular mass could be felt, freely movable in its bed.

The poor woman gradually sank, and died on March 12th, 1870.

During the post-mortem examination portions of skin from the chest and back, containing a number of the tumours, were removed for further examination. It was particularly noticed that the palms of the hands were free from the disease; but on the sole of one foot there was a rounded elevation, which seemed to be caused by the presence of one of the tumours. This was therefore removed, with the surrounding integument; but on careful dissection no tumour could be discovered, nor any explanation of the appearance observed in the post-mortem room.

The portions of integument taken from the chest and back were carefully dissected in the recent state. The skin was turned over, the subcutaneous textures were removed, and the tissue of the cutis was incised, so as to lay bare the various tumours. These differed greatly in position and size, but all of them were fixed to the cutis at one or more points on their superficial aspect. Except at these points, however, some of the largest tumours lay almost entirely in the subcutaneous tissue; these were soft, reddish bodies, with a smooth shining surface, and sometimes presented curious outgrowths, as may be seen in Plate VI, fig. 1. Other tumours lay imbedded in the substance of the corium itself, the under surface of which had to be incised before they came into view; these were generally paler and flatter, and 
seemed to be less sharply defined than those first described. The tumours which hung as stalked appendages from the cutaneous surface were not exposed until nearly the whole thickness of the skin was cut through towards the free surface. But when they were reached they were found to be very similar in character to those which were more deeply seated. They consisted of the same soft, reddish material, and did not seem to have become obsolete, or to have undergone degeneration, as might, perhaps, have been expected from their flaccid and shrivelled appearance.

But the matter of most interest was to determine the mode of development of the tumours. And, in the first place, it is to be remarked that the under surface of the integument was found to present a punctated appearance, which was quite peculiar. In the skin of the chest taken from a healthy individual the position of the hair-sacs is by no means obvious ; in this case each of them was visible as a greyish point. The skin thus acquired a dotted character, like that which belongs to orange-rind and to certain kinds of leather.

Among the smallest masses which could be recognised as constituting distinct tumours some were so remarkably elongated as to project in the form of smooth, greyish-pink, tongue-like bodies into the subcutaneous tissue. These presented the most favorable opportunities for tracing the earliest development of the disease. When such a little tumour was carefully dissected out, a minute yellowish point was always found in its interior, near its base. This yellowish point could often be seen with a lens, or even with the naked eye, to have a finely lobulated structure; it looked very like a portion of one of the Meibomian glands in the eyelids.

On removing one of these small tumours, with a very small piece of the skin to which it was attached, and flattening it by gentle compression on a microscopic slide, the following appearances were observed, which are shown in the accompanying figure (Plate VI, fig. 2).

Entering the base of the tumour was a fine hair, the root of which lay imbedded in the interior of the mass; no 
definite sac was observable from which this hair grew. Surrounding it was a beautiful arborescent glandular body, evidently developed from the sebaceous glands belonging to the follicle. It was this which constituted the yellowish point visible with the naked eye in the base of the tumour.

This glandular body was not only very much larger than a normal sebaceous gland from the same part of the body, it also presented much more numerous subdivisions, and these were more distinct and club-shaped in form.

The canal into which this glandular body opened, and in which the hair also lay, was in many of the tumours remarkably distinct, and very much wider than natural. Its size was, in fact, quite disproportionate to that of the hair, which thus bore nearly the same relation to the sebaceous glands which is normal in the skin of the nose.

The substance of the tumour itself appeared with a low power ( $\frac{2}{3}$-inch objective) to consist of a semi-transparent fibrillated material. Since it included not only the hair and the glandular body above described, but also the whole extent of the follicle, the tumour must necessarily at this point have come close to the surface of the derma, although (as already stated) the other end of it penetrated into the subcutaneous tissue.

The larger tumours were likewise found to contain yellow glandular points, resembling those found in the smaller ones, but in these the relations were somewhat more complicated. In no case did the growth of the glandular body advance much beyond the point which it had reached in the smaller tumours, and which is shown in Plate VI, fig. 2. The larger tumours thus consisted almost wholly of the fibrillated material above described; but their attached base (towards the cutaneous surface) always contained at least one glandular point. As a rule, indeed, several such glandular points were present in each of the larger tumours. I was unable to decide whether this arose from the coalescence of several distinct tumours, or from the gradual extension of the morbid growth, involving several hair-follicles in succession.

The observations above described were made by flattening 
the tumours (or portions of them) on microscopic slides, and examining them with a low power. They did not enable me to determine with certainty from what tissue the fibrillated material was developed which constituted the mass of the tumours. In the hope of throwing some light on this point, I prepared some hair-follicles and sebaceous glands from the skin of the chest of a healthy individual in precisely the same way. I then found that the tissue which immediately surrounded these was decidedly more transparent than that of the cutis generally, and it seemed to me that this must form the matrix from which the mass of the tumours arose.

Upon this question, however, much more light was thrown by some investigations made by my colleague $\mathrm{Mr}$. H. G. Howse, who had removed some of the tumours from the body of Sarah E-, and had hardened them in chromic acid, so that he was able to examine them by sections.

The following report was kindly furnished me by $\mathrm{Mr}$. Howse :

"The larger tumours were mainly made up of very fine connective tissue, in which an immense number of small oval corpuscles were disposed. These averaged a little over $\frac{1}{3000}$ th inch long and $\frac{1}{8000}$ th inch broad.

"The appearance of these corpuscles at first led me to suppose that they were the nuclei of involuntary muscular fibre. This, however, was disproved by the action of dilute nitric acid, which reagent was found to dissolve the intervening connective tissue, and to set the nuclei free; whereas it is well known that in the case of involuntary fibre the fibre-cells (and not the nuclei) are set free by nitric acid, unless, indeed, its action be too long continued.

"There was not any particular arrangement of this nucleated connective tissue, except that here and there it was disposed in bars across the preparation; these bars were also occasionally seen in tranverse section as circles, looking something like gland-tubes or vessels, from which, however, they were readily distinguished by their structure and by the absence of any central canal. 
"Around the masses of this nucleated connective tissue there were bundles of wavy fibrous tissue, such as is so abundant in the ordinary subcutaneous tissue.

"In each tumour which I examined there were also sections of hairs, sebaceous follicles, and sudoriparous gland-ducts. The sebaceous glands were rather larger than those seen in sections of healthy skin, taken from the same parts of the body and prepared for the purpose of instituting a careful comparison. This enlargement amounted in extreme cases to two or three times the normal size. The sebaceous glands in the tumours were also more sacculated, and the acini further separated from one another, than in the normal skin. Indeed, I did not make out that the bulk of the cavity of the gland was in any case much increased; its larger size was due rather to the growth of a tissue between the sacculi, dividing them from one another.

"The contents of the follicles remained unaltered, and consisted of glandular epithelium, containing in its interior the usual granular fatty matter peculiar to this part.

"It remains to be considered from what normal structure the nucleated tissue was developed which made up the bulk of the tumours. Now, so far as I am aware, there is only one place in the corium in which tissue exactly like this exists, namely, in the two external layers of the dermal coat of the hair-follicles, these being fibrous layers with oblong corpuscles, disposed circularly in one layer, longitudinally in the other. These layers are reflected over the sebaceous glands, the ducts of which join the follicle, although they are not so distinct over these glands as over the follicle itself. It is therefore probable, nay, almost certain, that the tumours of Molluscum Fibrosum are due to an hypertrophy of the two external coats of the hair-follicle, and especially of that part of these coats which goes over the sebaceous glands.

"If this view is correct, the larger tumours must consist of aggregations of smaller ones. I found sections of three or four different hairs in those which $I$ examined, which were all of them tumours of some size. It is probable that 
the above-described wavy bundles of white fibrous tissue contained in the tumours marked out the lines of separation between what were originally distinct centres of growth.

"I did not notice any alteration in the appearance of the sudoriparous gland-ducts contained in the tumours. It is probable, indeed, that their presence was accidental, and arose from their being, as it were, entangled between adjoining growths. In one or two cases I found a coil of gland-tube within a tumour. This, however, may be explained in the same way, for (as is well known) the external dense tissue of the corium occasionally holds sudoriparous coils, although these are most generally placed in the subcutaneous fat."

The conclusions arrived at by Mr. Howse and myself as to the nature and seat of Molluscum Fibrosum are, then, as follows :

1. That each tumour is originally developed round a hairfollicle, enclosing at the same time the sebaceous glands belonging to the follicle.

2. That the smaller tumours consist of two distinct elements :-a central glandular body, itself surrounding a hair; and a peripheral mass of very fiue connective tissue, containing numerous minute oval nuclei.

3. That the glandular body is a sebaceous gland, enlarged by the separation of its sacculi from one another, and perhaps also by the actual multiplication and increase in size of the sacculi themselves. The latter supposition is founded mainly on my own observations, made by flattening the smallest tumours en masse. The drawing which accompanies the paper appears to.me to show that the sacculi are more numerous and larger than in the normal integument. $\mathrm{Mr}$. Howse's accurate examinations of sections of the more advanced tumours failed, however, to determine the same fact.

4. That the peripheral mass of nucleated connective tissue is developed from the two external layers of the dermal coat of the hair-follicle and sebaceous glands. This point appears to be conclusively established by,Mr. Howse's observations, which (I may add) he has given me opportunities of confirming. 
The only difficulty which seems to stand in the way of the theory above laid down as to the nature of Molluscum Fibrosum is the fact that in some cases the tumours appear certainly to be developed in positions in which sebaceous glands are not known to exist, namely, in the integument of the palms and soles, and in the mucous membrane of the hard palate.

As regards the skin of the palms and soles, it is at least certain that the presence of the tumours of Molluscum in these regions is exceptional. In Dr. Beale's description of his case, which will hereafter be referred to, it is expressly stated that the palms of the hands and soles of the feet were free from the disease. They are so likewise in a patient (James Gray) now under my observation. But in another patient, a female who is also affected with well-marked Molluscum Fibrosum, two or three little tumours exist well within the margin of the palm of one hand. These tumours appear to be nearly as large as peas. It is true that their outline is less defined than that of tumours of the same size in other parts, but this may fairly be attributed to the difference in the character of the integument of the palm and in its relation to the subjacent tissues. I have already mentioned that in the case on which this paper is based there was apparently a growth in the sole of the foot, but that after its removal I could not discover any distinct tumour. It will be a point of great interest in future cases to examine any tumours of Molluscum that may appear to be developed in these regions.

Again, it has been pointed out to me by Mr. Hutchinson that in the case of James Gray, a man affected with Molluscum, of whom a portrait has been published by the New Sydenham Society, ${ }^{1}$ there exist beneath the mucous membrane of the hard palate two or three flattened movable tumours, apparently identical in nature with those of the skin. It is probable, I think, that these growths in the palate are developed round the glands of the mucous membrane in the same way as the cutaneous growths round the sebaceous glands.

1 Plate xvii. Catalogne, p. 58. 
The patient, James Gray, is at present an in-patient under my care in Guy's Hospital. And in regard to the disease in his case, I have observed one fact which appears to be strongly confirmatory of the view which I have put forth as to the nature of Molluscum. Almost all of the tumours-at any rate of those which have attained some size-have on their surface the orifices of several sebaceous glands. Now, the point to which I wish to draw attention is this, that if the skin over a tumour be grasped between the finger and thumb, so as to lift it off the tumour, one finds that the surface is puckered in at the site of each orifice, which thus forms the centre of a little hollow. It is therefore evident that the skin is more closely adherent to the tumour at these points than elsewhere, and this can hardly be explained in any other way than by supposing that the sebaceous glands are uniformly included in its interior.

The view which my observations have led me to take concerning the nature of Molluscum Fibrosum differs, I believe, essentially, not only from that generally entertained, but also from the opinions that have been advanced by any previous writer.

Willan and Bateman appear to have been the first to use the word Molluscum as a substantive. It had, however, been previously employed as an adjective by two writers, Plenck and Ludwig. The former" speaks of a "verruca carnea, seu mollusca. Est tuberculum molle, sensile, cuti concolor, vel rubens, sæpe pilosum. In naso et facie plurimum invenitur." Ludwig uses the expression "verrucis mollibus sive molluscis," in his preface to an essay by his pupil Tilesius.?

It is remarkable that, in these two passages, reference seems to be made to the two distinct diseases which have been included under the title of Molluscum. The definition of Plenck could hardly be applied to any disease but Molluscum Contagiosum; the case recorded by Tilesius

1 'Doctrina de morbis cutaneis,' p. 87. 1776.

2 'Historia pathologica singularis cutis turpitudinis.' Folio, Leipsico, 1793. vOL, LIII. 
appears certainly to have been one of Molluscum Fibrosum. The patient was a man, aged 50, whose body was covered with a number of tumours of very long duration, some having even existed at birth.

The recognition of the true nature of Tilesius's case is of some importance in reference to the history of Molluscum, for an erroneous interpretation of it appears to have been the cause of much of the confusion which has existed in regard to the affections known by this name. Bateman speaks of the tumours of Molluscum in general as containing "an atheromatous matter." In Tilesius's account of the case described by him it is noted that "in many of the larger tumours a small central aperture could be discovered, from which an oblong black body having a slender white root could be pressed out ; being, in fact, what is commonly called a comedo."

Now, by subsequent writers on this subject it was very early discovered that in ordinary cases of Molluscum the tumours are made up mainly of fibrous tissue, and do not contain any appreciable atheromatous matter. I have not been able to determine precisely who originally propounded the opinion that the tumours of ordinary Molluscum are essentially fibrous. But at any rate it was fully recognised by Simon, writing in 1851. This observer describes "Molluscum simplex seu non contagiosum," under the head of "Tumours consisting of Connective Tissue," while he places M. contagiosum in a different part of the work among "Sebaceous Tumours." In support of his opinion in regard to Molluscum simplex, he quotes the authority of MM. Cazenave et Schedel (1837), of Rokitansky, and of Krämer (1837).

It has already been remarked that Tilesius distinctly states that in his case bodies like comedones could be pressed out of the larger tumours. Hence it followed that both Cazenave ${ }^{2}$

1 'Die Hautkrankheiten durch anatomische Untersuchungen erläutert.' Berlin, 2te Auflage, 1851.

2 'Annales des Maladies de la Peau, et de la Syphilis,' vol. iii, 1850-51, p. 232. 
and Simon ${ }^{1}$-holding the opinion that in Molluscum simplex the tumours were simply fibrous-referred Tilesius's case to M. contagiosum, and not to M. simplex, to which (as it seems to me) it unquestionably belonged. Both these writers consequently supposed that the two diseases included under the head of Molluscum might present a much closer similarity of appearance than I believe to be really the case.

In the same year in which M. Cazenave's paper on Molluscum was published in the 'Annales des Maladies de la Peau,' another French dermatologist, M. Caillaut, communicated an essay to the 'Archives Générales' ${ }^{2}$. on the same disease. This writer regarded both the affections included under the title of Molluscum as affections of the sebaceous apparatus, and thus included both under the generic name of Acné, calling the one "A. molluscöide," the other A. pédiculée." The latter is the affection with which we are now concerned. Caillaut speaks of the smaller tumours, "which are pediculated and recent," as presenting follicular apertures, from which sebaceous matter can be pressed out. When of longer duration, he goes on to say, they lose these orifices, which become smaller and are at length obliterated. It is easy to trace these various stages in a patient who is covered with such tumours. "They are to be considered," he repeats, "as cysts resulting from the undue retention and accumulation of sebaceous matter in the cutaneous follicles." As might be expected, Tilesius's case is spoken of by Caillaut as an example of this disease.

The most cursory examination of the microscopical structure of the tumours of Molluscum Fibrosum could not fail to show the erroneousness of the opinion expressed by Caillaut in the passage above quoted, and accordingly I do not know that the writer of any later paper on this subject has committed a similar error. It is, however, remarkable that few dermatologists appear to have had opportunities of investigating the anatomy of Molluscum in the dead subject; with 
the exception of Förster (to whose paper I shall presently refer), authors have generally based their statements on the examination of tumours excised during the life of the patient.

This remark applies, for instance, to the very important observations made by Dr. Lionel Beale, and recorded by him in the "Transactions of the Pathological Society.' tumours which he examined were removed during life from a man, aged 60, by Mr. Bowman. The affection had commenced, thirty-seven years before, by the development of "small lumps in the skin, feeling like small shot when it was pinched." These little tumours had gradually been growing in size and in number ever since, but had given him no pain. The palms of the hands and soles of the feet were quite free from them.

From his examination of the tumours in this case Dr. Beale drew the following conclusions :

1. "That neither the sebaceous glands, nor the sweatglands, nor their ducts, were concerned in the formation of the tumours.

2. "That the tumour consisted essentially of a morbid alteration of the structures concerned in the formation of the hair, especially of the cells at the deepest part of the follicle, and of the follicle itself.

3. "That the subcutaneous areolar tissue was considerably hypertrophied, both its white and yellow elements being coarser and more abundant than in health."

It will be observed that, although Dr. Beale's conclusions accord with my own in fixing the seat of Molluscum as having a definite relation to the hair-sacs, they differ in attributing the development of the tumour to cells of epidermic nature rather than to the dermal layers of the follicle. With regard to the sebaceous glands, Dr. Beale's observations appear to have been less opposed to mine than would be inferred from the statements above quoted. "For the most part," he says, "the sebaceous glands were very distinct and easily

1 Vol. vi, 1855, p. 313. 
found. They opened into a very wide canal, which could be traced to the surface of the skin. . . . . In many instances all their structural elements were clear and well defined. In other cases they appeared to have been pressed upon by the growth of the tumour, and in consequence several of the follicles had been absorbed. . . . . In other instances the glandular follicles had been entirely removed, leaving the wide tube into which they had originally opened." Dr. Beale makes no mention of any growth of the glandular tissue such as was observed in my case above recorded.

It may be remarked that Dr. Beale entitles his case one of "Molluscum" simply, and this accords well with the practice of English writers in general, who until recently have been apt to overlook the distinctness of the two diseases included under that name. There is no doubt, however, that the case in question was really one of Molluscum Fibrosum.

Not only have Dr. Beale's observations received but little notice from the later writers (chiefly Germans) who have published investigations in regard to Molluscum, but the views expressed by these writers have uniformly been opposed to his, since they have regarded the disease as consisting simply in the development of scattered fibrous tumours indifferently among the layers of the cutis.

Among the most important of the writings in which these opinions are maintained is an essay by Prof. Förster. ${ }^{1}$ It is important, not only on account of the eminence of its author, but also because (as I have already remarked) it is perhaps the only paper that has hitherto been based on a post-mortem examination of a case of Molluscum. The disease is termed by Förster "Multiple Fibroma of the Skin." His description of it is quite definite and precise. He speaks of having had an opportunity, such as is rarely met with, of examining the disease in its very origin in the form of minute tumours scarcely visible to the naked eye. These all consisted of fully developed connective tissue, and were clearly seen to be

1 " Ueber die weichen Warzen und Mollnskenartigen Geschwülste der Haut.' ‘Wien. Med. Wchnschr.,' 8 u. 9, 1858. 
circumscribed growths of normal tissuc-elements of the deeper layers of the cutis ; the growth was in continuity with surrounding parts, and was not simply imbedded in them. In the skin covering the most minute tubercles there existed a small dark point resembling a comedo; but this was due to the fact that some of the tubercles developed themselves beneath or round hair-sacs, and as they gradually increased in size pushed the hair and its sebaceous glands upwards and to one side, or invested them entirely.

It will be seen that Prof. Förster's account of the structure of the smallest tumours above quoted is entirely inconsistent with my observations; nor, if the enlarged sebaceous glands, which were apparent to me, existed in his case, can I account for his having failed to discover them. It must therefore be left for future investigation to determine whether their presence is or is not constant.

The accounts given by later German writers have generally been in accordance with the statements of Förster. In the 'Krankhaften Geschwülste,'1 Virchow publishes two lithographic portraits of a case in which the patient was covered with the tumours of Molluscum, or, as he prefers to term it, Fibroma Molluscum. His investigation of the disease appears, however, to have been limited to the examination of some of the tumours removed during life.

Among the most recent publications on this subject is one by Dr. F. G. Pick, ${ }^{2}$ assistant to Prof. Hebra. This writer gives two cases. He cut off several of the tumours of various dates and sizes. They were very juicy, and of whitishyellow colour on section. They were found to consist in the centre of embryonal, towards the periphery of circularly arranged, fibrous connective tissue. Dr. Pick goes on to remark that Hebra has suggested that the simultaneous growth of these tumours in various parts of the body is due to a general morbid condition, for which we have at present no name. Both his patients were stunted. "One was fat and short, while his brothers were tall. The other resembled

1 Band I, p. 325.

2 'Wien. Med. Wehnschr.,' 1865, Juni, Nr. 49, p. 901. 
a Laplander, with crooked legs, high shoulders, \&c." Hebra has cven hinted at an alliance between Molluscum and Lepra Tuberculosa.

This account of the literature of Molluscum is not complete without a reference to a paper by Prof. Engel, ${ }^{1}$ although I believe that it has no real bearing on this subject. It is based on the examination of an old preparation in the Josefsakademie, of the nose of a man of middle age covered with numerous large pendulous tumours. These tumours presented large apertures of glands seated side by side. The glands are described as being enlarged and their acini multiplied, and the figures which Prof. Engel gives resemble very closely the appearances observed in the case which is the subject of my paper. But it is not clear to me that the sebaceous glands in this preparation were really larger than is natural in the skin of the region to which they belong, for it is well known that in the integument covering the nose these glands are much larger than elsewhere. Moreover, it is very doubtful whether the title of Molluscum can be justified, as applied to an affection which (so far as is known) was limited to the nose. The formation of pendulous tumours is common enough in extreme cases of Gutta Rosea, and it is to be expected that their structure should be precisely that described by Prof. Engel.

The view advanced in this paper as to the nature of Molluscum has the advantage of reconciling to a great extent the discrepancies in the opinions maintained by previous writers. Indeed, the only observations which appear to be absolutely opposed to mine are those of Prof. Förster above referred to. As, however, these seem to have been made with great care, they undoubtedly carry much weight. I therefore wish this communication to be takeh, at present, as simply referring to the case which I had an opportunity of examining, and not as necessarily applicable to all cases which may appear to present similar characters.

1 “ Untersuchung eines Falles von Molluskum." 'Wien. Med. Wchnschr.,' 1865, Nr. 82, p. 1485. 
It is evident that for any case resembling mine in its essential features the name of Molluscum Fibrosum is more appropriate than that of Fibroma Molluscum, used by Virchow and other German writers.

\section{DESCRIPTION OF PLATE VI.}

Fig. 1.-Portion of the skin of the back affected with molluscum fibrosum : the under surface dissected so as to expose the tumours lying at different depths in the substance of the skin. Natural size.

Fra. 2.-Microscopic appearance of one of the smallest tumours of molluscum; the entire tumour being simply flattened between two plates of glass. The accompanying scale represents hundredths of an inch. 

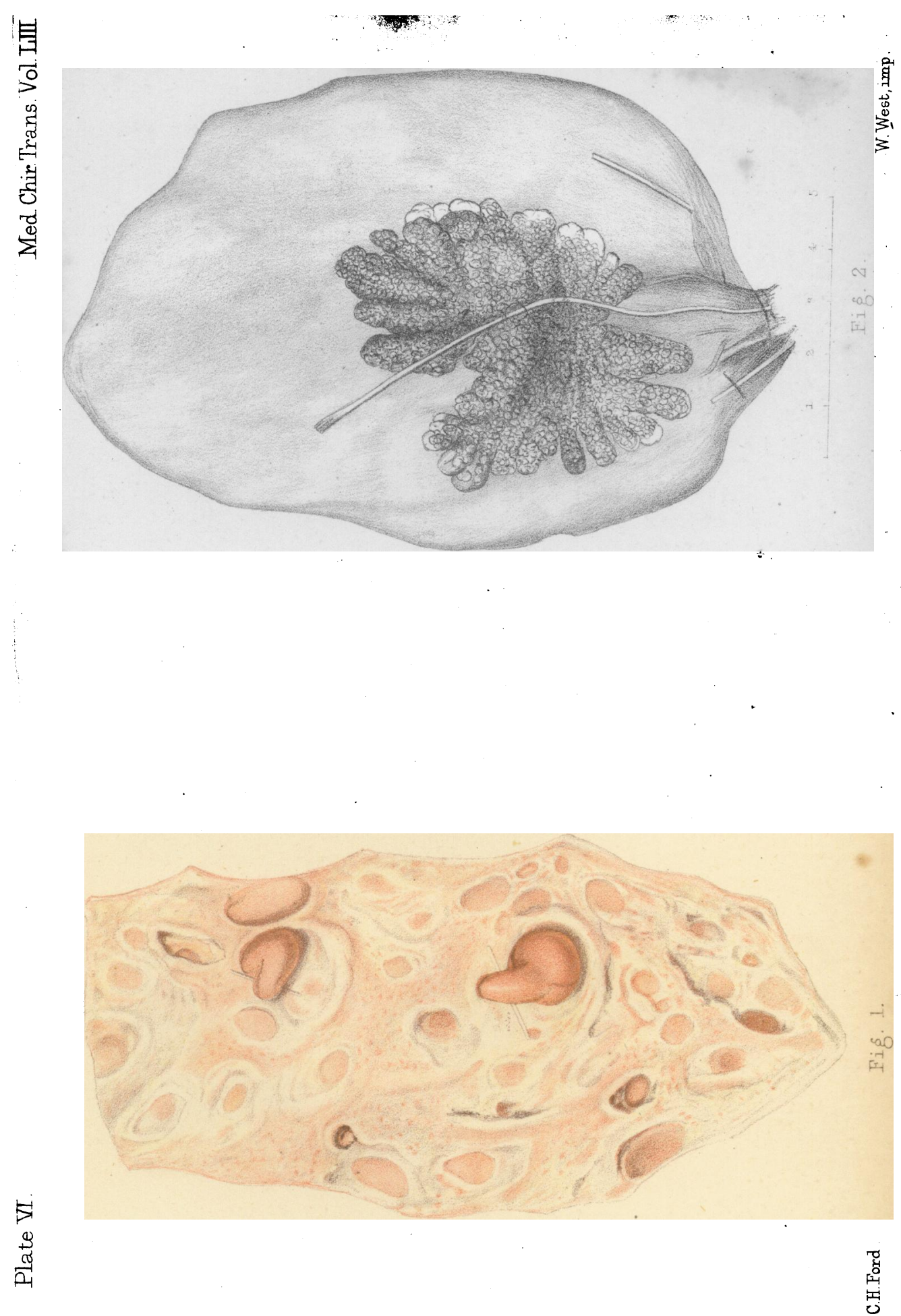